\title{
Inactivated Parapoxvirus ovis induces a transient increase in the expression of proinflammatory, Th1-related, and autoregulatory cytokines in mice
}

\author{
D. Anziliero ${ }^{1}$, R. Weiblen ${ }^{1}$, L.C. Kreutz ${ }^{2}$, F. Spilki $^{3}$ and E.F. Flores ${ }^{1}$ \\ ${ }^{1}$ Setor de Virologia, Departamento de Medicina Veterinária Preventiva, \\ Universidade Federal de Santa Maria, Santa Maria, RS, Brasi \\ ${ }^{2}$ Programa de Pós-Graduação em Bioexperimentação, Faculdade de Agronomia e Medicina Veterinária, \\ Universidade de Passo Fundo, Passo Fundo, RS, Brasil \\ ${ }^{3}$ Laboratório de Microbiologia Molecular, Instituto de Ciências da Saúde, Universidade Feevale, Novo Hamburgo, RS, Brasil
}

\begin{abstract}
The immunostimulatory properties of inactivated Parapoxvirus ovis (iPPVO) have long been investigated in different animal species and experimental settings. In this study, we investigated the effects of iPPVO on cytokine expression in mice after intraperitoneal inoculation. Spleen and sera collected from iPPVO-treated mice at intervals after inoculation were submitted to cytokine mRNA determination by real-time PCR (qPCR), serum protein concentration by ELISA, and interferon (IFN)- $\alpha / \beta$ activity by bioassay. The spleen of iPPVO-treated animals showed a significant increase in mRNA expression of all cytokines assayed, with different kinetics and magnitude. Proinflammatory cytokines interleukin (IL)-1 $\beta$, tumor necrosis factor-alpha (TNF- $\alpha$ ), and IL-8 mRNA peaked at 24 hours postinoculation (hpi; 5.4-fold increase) and 48 hpi (3- and 10-fold increases), respectively. A 15-fold increase in IFN- $\gamma$ and 6-fold IL-12 mRNA increase were detected at 48 and 24 hpi, respectively. Increased expression of autoregulatory cytokines (Th2), mainly IL-10 and IL-4, could be detected at later times (72 and 96 hpi) with peaks of 4.7- and 4.9-fold increases, respectively. IFN-I antiviral activity against encephalomyocarditis virus was demonstrated in sera of treated animals between 6 and $12 \mathrm{hpi}$, with a $>90 \%$ reduction in the number of plaques. Measurement of serum proteins by ELISA revealed increased levels of IL-1, TNF- $\alpha$, IL-12, IFN- $\gamma$, and IL-10, with kinetics similar to those observed by qPCR, especially for IL-12 and IFN- $\gamma$. These data demonstrate that iPPVO induced a transient and complex cytokine response, initially represented by Th1-related cytokines followed by autoregulatory and Th2 cytokines.
\end{abstract}

Key words: Cytokine; mRNA; ORF virus; Immunostimulant; Innate immune response

\section{Introduction}

Parapoxvirus ovis (PPVO or ORF virus) is a member of the genus Parapoxvirus within the family Poxviridae (1). PPVO is an important pathogen of sheep and goats distributed worldwide and produces a mucocutaneous, inflammatory, and proliferative disease known as contagious ecthyma, orf, or scabby mouth $(1,2)$. Occasionally, the virus is transmitted to humans, in which it produces vesiculopapular lesions on the hands and fingers (3). The 138-kb double-stranded DNA PPVO genome has been entirely sequenced and encodes more than 130 products, many with unknown functions (4). One interesting feature of PPVO is its ability to repeatedly infect the host in spite of a vigorous immune response $(5,6)$. Several immune-escape mechanisms and/or gene products have been identified in PPVO, including captured cellular genes [e.g., interleukin (IL)-1 homologue and granulocyte macrophage colonystimulating factor], an IL-2-inhibiting protein, the vaccinia E3L gene encoding an interferon (IFN)-resistance product (7), and several gene products interfering with the nuclear factor kappa beta (NF-kB) pathway (8-10). Nevertheless, the immune evasion by PPVO seems to be rather complex to be explained by a single factor or mechanism (6).

The immunomodulatory effects of PPVO have long been recognized and raised a significant interest in veterinary research in the last decades. Inactivated

Correspondence: E.F. Flores, Setor de Virologia, Departamento de Medicina Veterinária Preventiva, Universidade Federal de Santa Maria, Santa Maria, RS, Brasil. Fax: +55-55-3220-8055. E-mail: eduardofurtadoflores@gmail.com 
PPVO (iPPVO) retains many immunomodulatory properties of the live virus, suggesting that these effects should rely on the structural components of the viral particle. The effects of iPPVO on the innate immune response have been investigated in vitro in immune cells of several species and experimental settings. In summary, iPPVO exerts a strong effect on early cytokine secretion in mice and human cells, leading to an autoregulated loop of initial upregulation of inflammatory and Th1-related cytokines, followed by regulatory and Th2-related cytokines (11). Early proinflammatory cytokine secretion includes IL-6, IL-8, and tumor necrosis factor- $\alpha$ (TNF- $\alpha$ ) by monocytes and/or by antigen-presenting cells, IL-2, interferon type I (IFN-I) IFN- $\alpha / \beta$ and Th1 cytokines (IL-12, IL-16, IFN- $\gamma$ ) by $\mathrm{T}$ helper lymphocytes. IFN- $\gamma$ secretion by $\mathrm{T}$ lymphocytes or natural killer (NK) cells seems to be an important component of iPPVO activity (12-17). Most studies on immunomodulation by iPPVO have been conducted in vitro, yet the immunomodulatory effects of iPPVO have also been demonstrated in a few studies in vivo. For example, iPPVO has been shown to induce antiviral activity against genital herpes in a guinea pig model, in a transgenic mouse model of hepatitis $B$ virus, and in mice infected with herpes simplex virus (18). Studies addressing the immunomodulation by iPPVO in horses have demonstrated a balanced and early increase in cytokine production (19-21). Nevertheless, most studies on the effects of iPPVO on the innate immune response and the knowledge derived thereof were performed in vitro $(13,15,18-21)$.

In the present study, we investigated the effects of iPPVO on selected aspects of the innate immune response in mice using an in vivo approach. Groups of mice were inoculated with iPPVO, and samples collected at different intervals were tested for indicators of the innate immune response. Our previous study demonstrated that iPPVO stimulates phagocytosis, neutrophil oxidative bursts, serum bactericidal activity, and IFN- $\alpha / \beta$ production in treated mice (Anziliero $A$, unpublished results). In the present article, we describe a detailed investigation on the cytokine profile following iPPVO administration in mice, by real-time PCR (qPCR), ELISA, and IFN-I biological assays.

\section{Material and Methods}

\section{Experimental design}

Mice were inoculated with iPPVO [ $\log _{10}$ tissue culture infectious dose per $\mathrm{mL}\left(\mathrm{TCID}_{50}\right)$ of $\left.10^{7}\right]$ by the intraperitoneal (ip) route. Spleen and blood samples were collected at different times postinoculation [hours postinoculation (hpi) 6, 12, 24, 48, 72, 96, 120] and assayed for cytokine expression. Cytokine expression in the spleen (mRNA) was measured by qPCR, cytokines in sera were assayed by ELISA, and IFN-I activity in serum was investigated by a biological test.

\section{Animals}

All experiments used 6- to 8-week-old female Swiss mice (Mus musculus), weighing 23-30 g each. Animals were housed in plastic cages under controlled temperature $\left(20 \pm 2^{\circ} \mathrm{C}\right)$ with a $12: 12$-h light-dark cycle and access to food and water ad libitum. Ten mice per group were used in all experiments. The study was approved by the Institutional Ethics and Animal Welfare Committee, Universidade Federal de Santa Maria, Brazil (\#069/ 2011).

\section{Viruses and cells}

Viruses. Virus stocks used were ORFV IA-82 (passage 5 ), kindly provided by Dr. Daniel Rock (University of Illinois at Urbana, Champaign, IL, USA). Bovine herpes virus 1 (BoHV-1; Cooper strain) and the vaccinia virus (VACV) Brazilian isolate Pelotas 1 (22) were from our lab collection. The murine encephalomyocarditis virus (EMCV) was kindly provided by Dr. Erna G. Kroon (Universidade Federal de Minas Gerais, Brazil).

Cells. Primary ovine fetal turbinate cells (OFTu) were used to amplify ORFV IA-82, Madin-Darby bovine kidney (MDBK) cells were used for the amplification of BoHV-1, and Vero cells were used to amplify VACV. Cells were grown in Eagle's minimum essential medium (MEM) supplemented with $10 \%$ fetal bovine serum (FBS Nutricell, Brazil), $100 \mathrm{U} / \mathrm{mL}$ penicillin, and $100 \mu \mathrm{g} / \mathrm{mL}$ streptomycin, and maintained at $37^{\circ} \mathrm{C}$ and $5 \% \mathrm{CO}_{2}$.

\section{Preparation of iPPVO}

The iPPVO inoculum was prepared as follows. Briefly, ORFV strain IA-82, passage 10 , was propagated in primary OFTu and harvested when the cytopathic effect reached about $90 \%$ of the monolayer. The supernatant was collected and submitted to three cycles of freeze-thaw followed by centrifugation at low speed to remove cell debris. The supernatant was harvested and submitted to virus quantitation by limiting dilution, and virus titers were calculated (23) and reported as $\mathrm{TCID}_{50} / \mathrm{mL}$. The viral suspension was inactivated with binary ethylenimine (BEI) for 18-24 h at $37^{\circ} \mathrm{C}$. BEI $(0.1 \mathrm{M})$ was added to the virus suspension to a final concentration of $0.1 \%$, and residual $\mathrm{BEI}$ was hydrolyzed by the addition of $1 \mathrm{M}$ sterile sodium thiosulfate solution at a final concentration of $1 \%$. Viral particles in the suspension were then concentrated by ultracentrifugation at $116,939 \mathrm{~g}$ for $2 \mathrm{~h}$ at $4^{\circ} \mathrm{C}$ and stored at $-80^{\circ} \mathrm{C}$ until use. In all experiments, ultracentrifuged supernatant of mock-infected OFTu cells was used as control.

\section{Animal inoculation and sample collection}

Groups of mice were inoculated with iPPVO $\left(10^{7}\right.$ $\left.\mathrm{TCID}_{50}\right)$ ip in a volume of approximately $100 \mu \mathrm{L}$. At different times postinoculation $(6,12,24,48,72,96$, and $120 \mathrm{~h}$, depending on the experiment), blood samples and 
spleen tissue specimens were collected for the assays described below. All experiments (qPCR, ELISA, and IFN) included a mock-treated group (placebo) inoculated ip with ultracentrifuged supernatant of OFTu cells (5-7 mice/group). In experiments assayed for IFN-I, control groups included mice inoculated ip with inactivated BoHV-1 (iBoHV-1) and inactivated VACV (iVACV). The controls used (BoHV-1 and VACV) were submitted to the same process of inactivation described above for iPPVO.

For sample collection, animals were previously anesthetized with isoflurane by inhalation, followed by cervical dislocation. The animals were then necropsied for tissue collection at different intervals after iPPVO inoculation (12-120 hpi). Spleen specimens were collected rapidly and submitted to determination of amount of material (50 mg/animal). Specimens from individual animals were then placed in RNAlater stabilization reagent (Qiagen, USA) and stored at $-80^{\circ} \mathrm{C}$ until RNA extraction. Blood was collected from the cardiac chamber and left to clot overnight at $4^{\circ} \mathrm{C}$. The blood was then centrifuged for $20 \mathrm{~min}$ at $160 \mathrm{~g}$ for serum collection and stored at $-80^{\circ} \mathrm{C}$ for cytokine analysis.

\section{Cytokine mRNA expression}

RNA isolation and $c D N A$ synthesis. Isolation of total RNA was performed using the RNeasy mini kit from Qiagen, according to the manufacturer's instructions. The RNA concentration and purity were determined by the absorbance ratio at 280 and $260 \mathrm{~nm}$. RNA integrity was assessed by denaturing gel electrophoresis on $1 \%$ agarose gel stained with ethidium bromide. All samples were treated with amplification-grade DNase I (Invitrogen, USA) to remove traces of genomic DNA contamination (24). According to RNA concentrations, treated RNA concentration was adjusted for $1 \mu \mathrm{g}$ RNA per sample.

RNA samples were reverse transcribed (RT) using the SuperScript ${ }^{\mathrm{TM}}$ III First-Strand Synthesis System for RT-PCR (Invitrogen) according to the manufacturer's instructions. Briefly, $1 \mu \mathrm{g}$ DNase-treated RNA was mixed with $1 \mu \mathrm{L}$ oligo(dT) 20 primer $(50 \mu \mathrm{M})$ and $1 \mu \mathrm{L}$ dNTP mix $(10 \mathrm{mM})$ and completed up to $10 \mu \mathrm{L}$ with DNase/RNasefree water. Samples were heated at $65^{\circ} \mathrm{C}$ for $5 \mathrm{~min}$ and subsequently cooled on ice for $1 \mathrm{~min}$. After that, $10 \mu \mathrm{L}$ cDNA synthesis mix (RT buffer, $\mathrm{MgCl}_{2}$, Superscript III RT, DTT, and RNaseOUT) was added to the RNA/primer, mixed gently, and collected by brief centrifugation. The reaction was incubated again at $50^{\circ} \mathrm{C}$ for 50 min followed by heating at $85^{\circ} \mathrm{C}$ for 5 min and chilled on ice. To remove RNA template from cDNA, $2 \mu \mathrm{L}$ RNase $\mathrm{H}$ was added to the mixture to a final volume of $22 \mu \mathrm{L}$. A work solution was prepared diluting cDNA 1:20 in DNA/RNA-free water. For every reaction set, one RNA sample was performed without Superscript II RT (RT-minus reaction) to provide a negative control in the subsequent qPCR. The cDNA was stored at $-80^{\circ} \mathrm{C}$ until qPCR assays.

\section{Quantification of cytokine mRNA expression by qPCR}

Relative gene expression was assayed by qPCR using the iCycler iQ5 RT-PCR system (Bio-Rad, USA) using standard conditions. All samples were analyzed in triplicate. Each reaction contained $12.5 \mu \mathrm{L}$ Maxima SYBR Green/ROX qPCR Master Mix (Thermo Scientific, USA), $8 \mu \mathrm{L}$ water, $1 \mu \mathrm{L}$ forward primer $(20 \mu \mathrm{M}), 1 \mu \mathrm{L}$ reverse primer $(20 \mu \mathrm{M})$, and $2.5 \mu \mathrm{L}$ cDNA. Custom-made specific primers and internal controls for all targets were designed using the Primer3 Input online program (http://fokker.wi. mit.edu/primer3/input.htm). The specific annealing of the designed primers to the mRNA targets was previously analyzed by BLAST (25). Primers/amplicons were validated using a melting curve analysis, and two housekeeping genes [glyceraldehyde 3-phosphate dehydrogenase (GAPDH) and $\beta$-actin] were evaluated to select the best internal control. The sequences of primers used in this study are listed in Table 1 . The reaction was carried out as follows: $50^{\circ} \mathrm{C}$ for $2 \mathrm{~min}, 95^{\circ} \mathrm{C}$ for $10 \mathrm{~min}, 40$ cycles at $95^{\circ} \mathrm{C}$ for $20 \mathrm{~s}$, and $59^{\circ} \mathrm{C}$ for $1 \mathrm{~min}$. Melting curve analyses were performed immediately after amplification by an additional denaturation at $95^{\circ} \mathrm{C}$ and continuous melting curve acquisition from $55^{\circ}$ to $95^{\circ} \mathrm{C}$ with a $1^{\circ} \mathrm{C} / \mathrm{s}$ ramp rate to verify product specificity. Changes in cytokine gene expression were calculated by relative quantitation using the $\Delta \Delta \mathrm{Ct}$ (threshold cycle) method (26), where $\Delta \Delta \mathrm{Ct}=$ iPPVO (cytokine gene ${ }^{\Delta \mathrm{Ct}}$ minus housekeeping gene ${ }^{\Delta \mathrm{Ct}}$ ) minus control (cytokine gene ${ }^{\Delta \mathrm{Ct}}$ minus housekeeping gene $\left.^{\Delta \mathrm{C}}\right)$. Treatment-induced changes in cytokine gene expression for each individual sample were calculated using $2^{-\Delta \Delta \mathrm{Ct}}$. Results are reported as means \pm SE foldchange in cytokine gene expression from the iPPVO group over the control group. To determine the efficiency of the qPCR assays, 2-fold serial dilutions of cDNA samples were used, with the $\mathrm{Ct}$ of each dilution being defined and plotted on a semi-log $(\log 10)$ graph for analysis. The slopes of accurate tendency lines $\left(r^{2} \geqslant 0.98\right)$ were used to determine the efficiency of the reactions $\left(E=-1+10^{(-1 / \text { slope })}\right)$. Means \pm SE were calculated for each group, and results are reported as times-fold increase (iPPVO-treated relative to controls).

\section{Cytokine measurement}

Serum samples collected from iPPVO-inoculated and control mice at different intervals were submitted to cytokine determination by ELISA. To ensure specificity of the iPPVO effect, control groups included mice inoculated ip with iBoHV, iVACV, and ultracentrifuged supernatant of mock-infected OFTu cells. Cytokines related to the innate immune response (IL-1 $1 \beta$, IL-12, TNF- $\alpha$, IFN- $\gamma$, and IL-10) were assayed using a mouse cytokine enzyme immunoassay kit (BD Biosciences, USA). Briefly, $100 \mu \mathrm{L}$ capture antibodies for each cytokine were diluted in coating buffer (0.2 $\mathrm{M}$ sodium phosphate, $\mathrm{pH} 6.5,11.8 \mathrm{~g} \mathrm{Na}_{2} \mathrm{HPO}_{4}$, $16.1 \mathrm{~g} \mathrm{NaH}_{2} \mathrm{PO}_{4}$, sufficient quantity to 1 liter, $\mathrm{pH} 6.5$ ), coated on ELISA plates (Nunc, USA), incubated overnight 
Table 1. Primer pairs used in $\mathrm{qPCR}$ for determination of cytokine mRNAs.

\begin{tabular}{|c|c|c|}
\hline Target & Primer sequence $\left(5^{\prime}-3^{\prime}\right)$ & Product size (bp) \\
\hline \multirow[t]{2}{*}{ GAPDH } & F: CAGCCTCGTCCCGTAGACAA & 178 \\
\hline & R: ACCCCGTCTCCGGAGTCCATCACAAT & \\
\hline \multirow[t]{2}{*}{$\beta$-actin } & F: AGGCCAACCGTGAAAAGATGACCCAGAT & 139 \\
\hline & R: GTAGACCATGTAGTTGAGGTCAATGAA & \\
\hline \multirow[t]{2}{*}{$\mathrm{IL}-1 \beta$} & F : TGGCCTTCAAAGGAAAGAATCTATACCTGTCC & 179 \\
\hline & R: GTTGGGGAACTCTGCAGACTCAAACTCCAC & \\
\hline \multirow[t]{2}{*}{ IL-8 } & F: GACGCCCCCAGGACCCCACTG & 162 \\
\hline & R: AGCCCAGGCTCCTCCTTTCCAGGTC & \\
\hline \multirow[t]{2}{*}{ TNF- $\alpha$} & F: CAGGCCTTCCTACCTTCAGACCTTTCCAGAT & 166 \\
\hline & R: ACACCCCGCCCTTCCAAATAAATACATTCAT & \\
\hline \multirow[t]{2}{*}{ IL-12p40 } & F: TGCCCCCACAGAAGACGTCTTTGATGAT & 158 \\
\hline & R: GATGGCCACCAGCATGCCCTTGTC & \\
\hline \multirow[t]{2}{*}{ IFN- $\gamma$} & F: GCCAAGACTGTGATTGCGGGGTTGTATCT & 178 \\
\hline & R: TAAAGCGCTGGCCCGGAGTGTAGACA & \\
\hline \multirow[t]{2}{*}{ IL-10 } & F: AGCTGCAGGGCCCTTTGCTATGGTG & 180 \\
\hline & R: GATGAAGCGGCTGGGGGATGACAGTA & \\
\hline \multirow[t]{2}{*}{ IL-4 } & F: CACTGAGAATGAAAGGCCCCAAAGTCTTGA & 168 \\
\hline & R: AGCCGGGAGGACAGATCTCTGGTGAAG & \\
\hline
\end{tabular}

GAPDH: glyceraldehyde 3-phosphate dehydrogenase; IL: interleukin; IL-12p40: IL-12, subunit p40; TNF- $\alpha$ : tumor necrosis factoralpha; IFN- $\gamma$ : interferon gamma; $F$ and $\mathrm{R}$ : forward and reverse primers, respectively.

at $4{ }^{\circ} \mathrm{C}$, and then washed 3 times (PBS with $0.05 \%$ Tween20, freshly prepared). Plates were blocked with $200 \mu \mathrm{L} /$ well PBS with $10 \%$ FBS, pH 7.0, and incubated at room temperature for $1 \mathrm{~h}$. After that, microplates were washed again (3 times) while samples and standard curve dilution were prepared following the manufacturer's recommendations. Then, $100 \mu \mathrm{L}$ serum sample and standard curve dilutions for each cytokine were added in duplicate to plates and incubated at room temperature for $2 \mathrm{~h}$. Plates were washed 5 times and blotted to remove any residual content, and $100 \mu \mathrm{L}$ working detector solution (detection antibody + streptavidin-horseradish peroxidase reagent) was added to the wells and incubated for $1 \mathrm{~h}$ at room temperature. Wells were aspirated and plates were washed again ( 7 times), and $100 \mu \mathrm{L}$ substrate solution (tetramethylbenzidine and hydrogen peroxide) was added. The solution was incubated for $30 \mathrm{~min}$ at room temperature in a dark chamber. Finally, the reaction was stopped by adding $50 \mu \mathrm{L}$ stop solution, and the absorbance was measured at $450 \mathrm{~nm}$. Absorbance was transformed to cytokine concentrations $(\mathrm{pg} / \mathrm{mL})$ using the detection limits assessed from the standard curve for each cytokine. Results are reported as means $\pm \mathrm{SE} \mathrm{pg} / \mathrm{mL}$. Results were submitted to statistical analysis by the Shapiro-Wilk test to verify normality, followed by the Student $t$-test to compare mean values between groups. Statistical significance was accepted as $\mathrm{P}<0.05$.

\section{IFN-I assays}

Serum samples obtained at different times postinoculation (6, 12, $24 \mathrm{hpi})$ from mice inoculated with iPPVO or controls (iBoHV-1 and iVACV) were assayed for IFN-I activity against murine EMCV according to a previous study (27). An IFN standard (IFN- $\beta^{r}$ ) was included in all assays to monitor cell conditions and reproducibility.

Confluent $\mathrm{L}_{929}$ cells $\left(2 \times 10^{6}\right.$ cells $\left./ \mathrm{mL}\right)$ grown on 96 -well plates were incubated with 2-fold dilutions of mouse sera for $6 \mathrm{~h}$. Plates were then drained, washed 3 times with MEM, inoculated with $100 \mathrm{TCID}_{50} \mathrm{EMCV}$, and incubated for $2 \mathrm{~h}$ at $37^{\circ} \mathrm{C}$. The inoculum was removed and cells were washed 3 times and incubated with culture medium containing $2 \%$ FBS for $48 \mathrm{~h}$ and monitored for the EMCV cytopathic effect. IFN activity was expressed as the reciprocal of the serum dilution that produced an inhibition of the cytopathic effect in $50 \%$ of the cell monolayers. Results are reported as $\log _{2}$ of geometric mean titers.

Antiviral activity of IFN-I was also determined by plaque reduction assay (28) comparing both groups (iPPVO vs control). Briefly, L $_{929}$ cells were seeded onto 6 -well plates at a density of $1 \times 10^{6}$ per well on the day before the experiment. On the following day, the medium was removed and cells were washed 3 times with medium and incubated with duplicates of mouse serum diluted 1:10 (MEM) for $6 \mathrm{~h}$. In addition to mock controls, monolayers were inoculated with sera of mice inoculated with iBoHV-1 and iVACV. Cells were then drained, washed 3 times, and inoculated with $100 \mathrm{TCID}_{50}$ EMCV. After $2 \mathrm{~h}$ of adsorption at $37^{\circ} \mathrm{C}$, cultures were washed and overlaid with MEM supplemented with $2 \% \mathrm{FBS}$ and incubated for $48 \mathrm{~h}$ at $37^{\circ} \mathrm{C}$ and $5 \% \quad \mathrm{CO}_{2}$. After that, monolayers were fixed with formalin $(10 \%)$ and stained with crystal violet $(0.3 \%)$ for $2 \mathrm{~h}$. The percentage inhibition of plaque formation was calculated as follows: [(mean number of plaques in 
control)-(mean number of plaques in sample)] $\times 100 /$ (mean number of plaques in control). Viral plaques were counted for each replicate, and results are reported as the percentage of plaque reduction and means $\pm S E$.

\section{Results}

\section{Standardization of PCR conditions by conventional PCR}

Initially, a conventional PCR was performed using iPPVO and control DNA samples to verify the specificity and functionality of the primers and to optimize the PCR conditions. PCR settings were considered satisfactory when a single well-defined band was observed after electrophoresis on $1 \%$ agarose gel. Based on the efficiency of amplification and variability results, GAPDH was selected as the housekeeping control gene for qPCR. During the entire experiment, an adequate PCR amplification efficiency was determined by the slope of the standard curves (between -3.3 and -3.7), and linear regression analysis showed that all standard curves had an $r^{2}$ value of $\geqslant 0.98$ (data not shown).

\section{Cytokine mRNA expression upon iPPVO stimulation}

Standardized qPCR was then used to measure the expression of cytokine mRNAs in total RNA extracted from the spleen of mice inoculated with iPPVO. qPCR was performed in total RNA extracted from spleens collected from mice at different times postinoculation. For this purpose, cytokines from the proinflammatory route (IL-1 $\beta, \mathrm{IL}-8$, and TNF- $\alpha$ ), Th1 type (IFN- $\gamma, \mathrm{IL}-12$ ), and regulatory Th2 (IL-4 and IL-10) were selected. The results of qPCR for cytokine mRNAs are shown by groups of cytokines (IL-1 $\beta, \mathrm{IL}-8$, and TNF- $\alpha$ ), Th1 type (IFN- $\gamma$, $\mathrm{IL}-12$ ), and Th2 (IL-4 and IL-10) in Figures $1 \mathrm{~A}, 2 \mathrm{~A}$, and $3 A$, respectively. Controls included spleen obtained from mice inoculated with the supernatant of iPPVO ultracentrifugation tested at the same intervals.

Increased expression of proinflammatory cytokines (mRNA) was first detected for IL-8 at 12 hpi, with a 4-fold increase over the controls (Figure 1A). At this time, expression of TNF- $\alpha$ and IL-1 $\beta$ mRNA remained unaltered. At $24 \mathrm{hpi}$, all three mRNAs were increased (>5-fold increase for IL-1 $\beta$, 2-fold increase for TNF- $\alpha$, and 4-fold increase for IL-8, Figure 1A). High IL-1 $\beta$ expression was detected up to $96 \mathrm{hpi}$, with a progressive reduction in magnitude of expression observed over time ( $>5$-fold at $24 \mathrm{hpi}$ to $<3$-fold at $96 \mathrm{hpi}$ ). Expression of TNF- $\alpha$ remained within the range of a 2- to 3-fold increase over the period. IL-8 expression remained high during the period, with a strong peak at $48 \mathrm{~h}$ ( $>10$-fold). Increased expression of these mRNAs could no longer be detected after $96 \mathrm{hpi}$, indicating a short-term induction.

Enhanced expression of IFN- $\gamma$ and IL-12 mRNA was first detected at $24 \mathrm{hpi}$, with 3 -fold and $<6$-fold increases, respectively. IL-12 expression showed a slight reduction
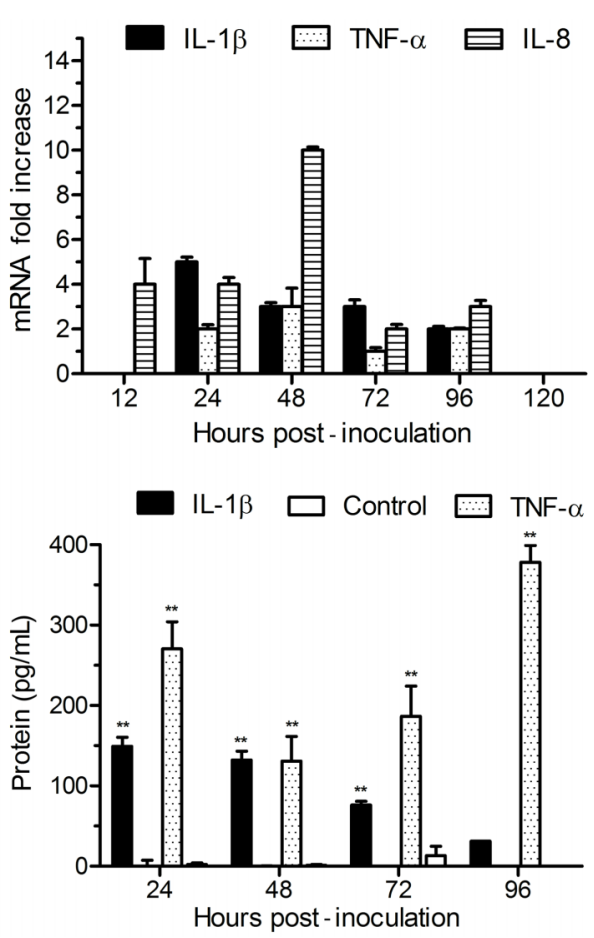

Figure 1. Proinflammatory cytokines measured by qPCR in mice spleen $(A)$ and by ELISA in serum samples $(B)$ at different time points after inactivated Parapoxvirus ovis inoculation. IL-1 $\beta$ mRNA was measured up to 120 hours post-inoculation. IL: interleukin; TNF- $\alpha$ : tumor necrosis factor-alpha. Data are reported as means \pm SE as times-fold increase over the control group (qPCR) and as $\mathrm{pg} / \mathrm{mL}$ serum protein in ELISA. ${ }^{*} \mathrm{P} \leq 0.01$, iPPVO compared to control ( $t$-test).

by $48 \mathrm{hpi}$, but remained above the control values (2- to 4fold) up to 96 hpi (Figure 2A). IFN- $\gamma$ expression presented a strong peak at $48 \mathrm{hpi}$ (15-fold), returning to lower levels, but still above the controls at 72 and 96 hpi. Both mRNAs returned to base levels at $120 \mathrm{hpi}$.

mRNA levels of regulatory Th2 cytokines remained within basal levels for the first $48 \mathrm{~h}$ after iPPVO inoculation. Then, a strong pulse of expression of IL-4 mRNA was detected at 72 hpi (5-fold), reducing to 2.5fold at 96 hpi (Figure 3A). IL-10 expression showed an opposite behavior, with a moderate increase at $72 \mathrm{hpi}$ (1.5-fold) and a marked increase at $96 \mathrm{hpi}$ (4.5-fold). The two mRNAs were below detection limits at $120 \mathrm{hpi}$.

Taken together, these results showed that iPPVO stimulation resulted in a time-dependent, transient, and autoregulatory increase in expression of several classes of cytokines. The kinetics and magnitude of the stimulation effects varied according to the respective cytokine group and was first observed for IL-8 at 12 hpi. Most proinflammatory and Th1 cytokines showed a peak in expression at 24 and $48 \mathrm{hpi}$, whereas Th2-regulatory cytokines peaked at $72 \mathrm{~h}$ and $96 \mathrm{hpi}$. Expression of all tested cytokines returned to steady state at $120 \mathrm{hpi}$. 

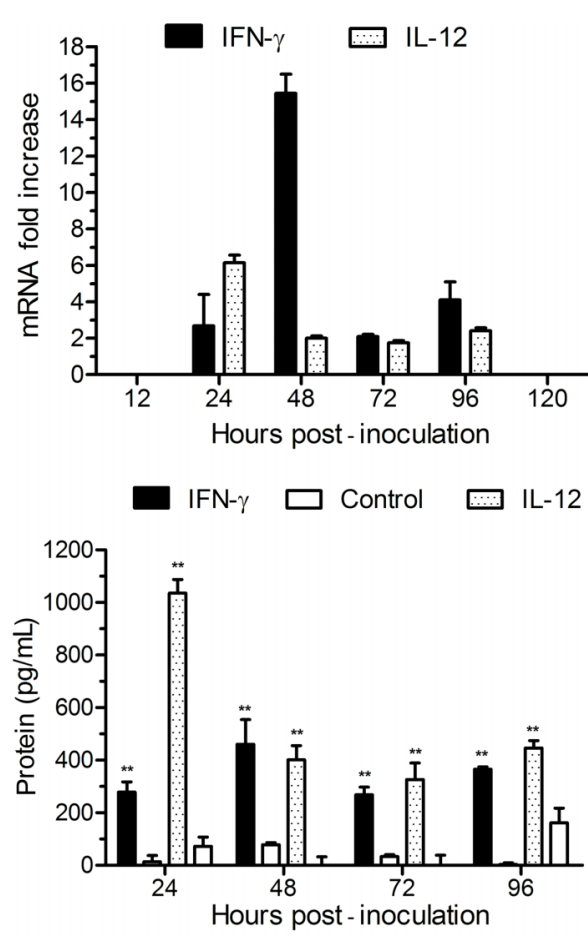

Figure 2. Th1-related cytokines in the spleen of mice measured by GPCR $(A)$ and serum levels of protein assayed by ELISA $(B)$ at different time points after inoculation with inactivated Parapoxvirus ovis. IL: interleukin; IFN- $\gamma$ : interferon gamma. Data are reported as means $\pm \mathrm{SE}$ as times-fold increase over the control group (qPCR) and as $\mathrm{pg} / \mathrm{mL}$ serum protein in ELISA. ${ }^{* *} \mathrm{P} \leq 0.01$, iPPVO compared to control (t-test).

\section{Cytokine levels in sera}

To further investigate the effects of iPPVO in cytokine expression, individual concentrations in sera were measured by ELISA at different time points, except for IL-8 and IL-4. Results were calculated as the mean absorbance for each set of duplicate standards minus the mean zero standard absorbance. The standard curve absorbance values were plotted on a log-log graph to determine cytokine concentrations over sample absorbance. The levels of the respective groups of cytokines in sera at different intervals after iPPVO inoculation are reported in Figures 1B, 2B, and 3B. A marked increase in cytokine levels was detected in iPPVO-treated animals compared to control/placebo groups for all cytokines assayed, with the profile varying according to the respective cytokine. Among proinflammatory cytokines, levels of IL-1 $\beta$ were high from 24 to $72 \mathrm{hpi}$, presenting a progressive reduction toward near-basal levels at 96 hpi. TNF- $\alpha$ levels also remained high, with peaks at 24 and 96 hpi. Among Th1-related cytokines, a peak in IL-12 subunit p40 (IL12p40) was noted at $24 \mathrm{hpi}$, with levels reducing, yet remaining at relatively high levels up to $96 \mathrm{hpi}$. IFN- $\gamma$ levels were also increased during the entire period, with a slight peak at $48 \mathrm{hpi}$. Among the Th2 cytokines, only IL-10 was measured, presenting increased levels from 48 to $96 \mathrm{hpi}$,
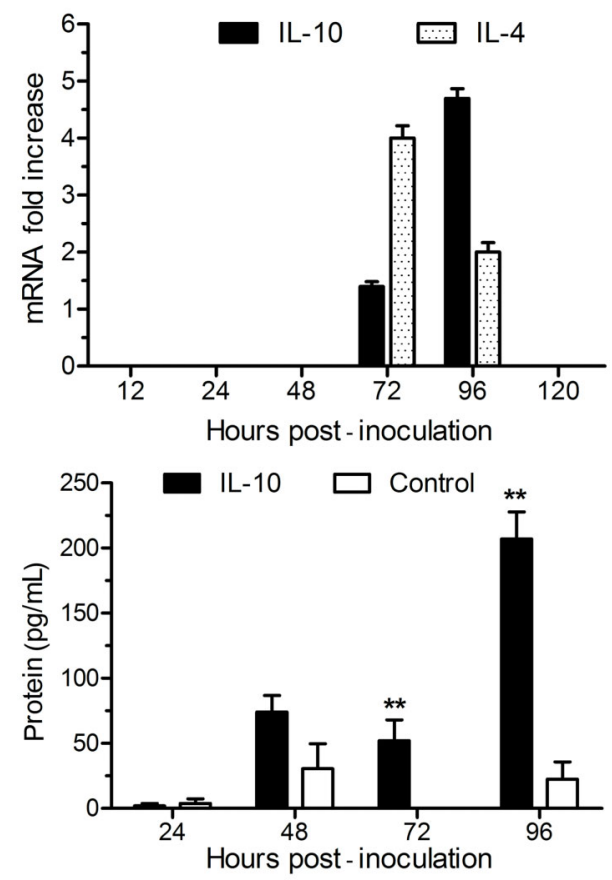

Figure 3. Quantification of mRNA Th2 cytokines in spleen of mice inoculated with inactivated Parapoxvirus ovis (iPPVO) at different intervals. Data are reported as means \pm SE as times-fold increase over the control group $(A)$. IL-10 mRNA was measured up to 120 hpi. Panel $B$ reports the levels of IL-10 in the sera of mice after inoculation of iPPVO, measured by ELISA. IL: interleukin. Data are reported as means $\pm \mathrm{SE}$ as $\mathrm{pg} / \mathrm{mL}$ serum protein. ${ }^{* *} \mathrm{P} \leq 0.01$, iPPVO compared to control ( $t$-test).

with a late peak (96 hpi). Consistent with mRNA findings, measurement of $\mathrm{IL}-1 \beta$, TNF- $\alpha$, IL-12, IFN- $\gamma$, and IL-10 protein levels in sera confirmed the qPCR results (Figures 1, 2 , and 3 ), indicating a broad spectrum of cytokine response following iPPVO stimulation. With the exception of IL-8, the profile of mRNA expression and cytokine detection in sera were roughly similar. Using the supernatant of iPPVO ultracentrifugation and large viruses (BoHV-1 and VACV) submitted to the same process of preparation and inactivation of iPPVO, no stimulation over the innate immune cytokines could be detected, confirming that the immunomodulation is iPPVO specific.

\section{IFN-I induction}

The production of IFN-I by iPPVO-treated mice was assayed by investigating IFN-I activity in a biological assay against EMCV $(27,28)$. Inhibition of EMCV replication was detected in sera collected 6 to $24 \mathrm{~h}$ after iPPVO inoculation, with a peak in antiviral activity observed between 6 and 12 hpi. At 24 hpi, sera from 2 of 6 animals exhibited antiviral effects. Murine internal laboratory standard recombinant interferon $\left(\mathrm{IFN}^{r}\right)$ provided intraassay and interassay controls during the experiment. No antiviral activity was detected in sera collected from mice 
inoculated with MEM, supernatant from mock-infected OFTu cells and from ultracentrifugation of iPPVO, iBoHV1, or iVACV. Thus, the inhibitory effect of EMCV replication seems to be specific to iPPVO stimulation. To better characterize the inhibitory IFN activity on EMCV replication, a plaque reduction assay was performed. Again, a marked inhibitory effect on EMCV replication was observed in sera collected at $6 \mathrm{hpi}$ from mice inoculated with iPPVO. The $>94 \%$ plaque reduction observed at $6 \mathrm{hpi}$ decreased to $28 \%$ at $12 \mathrm{hpi}$ and was no longer observed at $24 \mathrm{hpi}$. No plaque reduction was observed in the sera of mice inoculated with iBoHV-1 or iVACV, indicating an iPPVO-specific effect. These results indicate that iPPVO inoculation leads to a significant and transient increase in IFN-I production, as measured by the IFN-I inhibitory effect on EMCV replication, which seems to be iPPVO specific rather than a general response to inoculation of inactivated viral particles.

\section{Discussion}

Our results demonstrated that iPPVO administration leads to a transient and coordinated increase in the expression of several cytokines in mice, as measured by qPCR, biological assays (IFN-I), and ELISA. The kinetics and magnitude of the effects varied according to the cytokine group. Increased expression levels were detected as early as $6 \mathrm{hpi}$ for IFN-I and at $12 \mathrm{hpi}$ for IL-8. The cytokine levels were, in general, maintained above normal limits for up to $72-96 \mathrm{~h}$, returning to basal levels at measurements performed at $120 \mathrm{hpi}$. Most proinflammatory and Th1 cytokines increased from 24 to $96 \mathrm{hpi}$, with a peak between 24 and 48 hpi. Regulatory and Th2 cytokines peaked later, at 72 and 96 hpi. These results from in vivo iPPVO stimulation confirm and extend previous results from in vitro studies, demonstrating a broad stimulatory effect on proinflammatory and Th1- and Th2related cytokines. These effects would likely contribute to the immunostimulatory properties of iPPVO observed in several animal species. However, a comprehensive understanding of the immunological mechanisms underlying these effects still represents a challenge toward an adequate use of iPPVO as immunostimulant in animal and human infectious diseases.

The immunostimulant properties of iPPVO have long been recognized and paved the way for its use as a commercial stimulator of the innate immune response (Baypamun ${ }^{\mathbb{R}}$, Compind, Zylexis ${ }^{\mathbb{R}}$ ). Immune modulation by iPPVO has been investigated in several systems and was primarily associated with stimulation of a broad range of cytokines, including proinflammatory and Th1- and Th2-related cytokines (29). This complex cytokine response is also associated with the activation of several cell populations, including monocytes and Th1-like cells, human neutrophils, canine monocytes, and murine bone marrow-derived dendritic cells (BMDCs), among others
$(13,15-18,29,30)$. Most of these studies focused on in vitro stimulation of specific cell populations by preparations of iPPVO. In a previous study, we demonstrated that iPPVO administration to mice resulted in increased phagocytosis in vitro and in vivo by macrophages, enhanced neutrophil oxidative bursts, serum bactericidal activity, and IFN- $\alpha / \beta$ production (Anziliero $A$, unpublished results). The present study investigated the effects of iPPVO stimulation on the expression of selected cytokines after in vivo exposure.

Our results confirmed previous findings (Anziliero A, unpublished results) and demonstrated a prompt and transient IFN-I response, peaking at $6 \mathrm{hpi}$ and remaining up to $24 \mathrm{hpi}$. Previous studies have demonstrated that peripheral blood mononuclear cells (PBMCs) and BMDCs exposed to iPPVO in vitro produced IFN-I in the range of 6 and 24 hpi $(17,19,30)$. Also confirming earlier in vitro studies (13,18, and Anziliero A, unpublished results), the IFN-I-stimulatory effect seems to be iPPVO specific, since it was not detected upon iBoHV-1 or iVACV inoculation. Although transient, IFN-I induction/activity may trigger downstream mechanisms involved in microbial resistance and clearance by the immune system. It is also possible that the cascade of antiviral genes activated by the IFN system contributed to the broad cytokine responses observed at later times after iPPVO stimulation.

An early increase in proinflammatory cytokines was a consistent finding in the present study (Figure 1). Increased IL-8 mRNA expression was detected as early as $12 \mathrm{hpi}$, followed by increased expression of IL-1 $\beta$ and TNF- $\alpha$. In fact, iPPVO immune modulation in vitro has been associated with the production of proinflammatory cytokines (IL-6, IL-8, TNF- $\alpha$ ) by monocytes or antigenpresenting cells $(17,30)$. Mouse BMDC respond in vitro to iPPVO secreting TNF- $\alpha$ and IL-12p40 (17). In addition, local TNF- $\alpha$ induction and increased levels in the blood have been demonstrated in horses 24-48 h after intradermal or intramuscular iPPVO administration, respectively (29). Thus, an early induction of proinflammatory cytokines in immune cells appears to be a common effect of iPPVO stimulation both in vivo and in vitro.

Cytokines TNF- $\alpha, \mathrm{IL}-1 \beta$, and IL- 8 mediate the initial response of the innate immune system to a challenge, infection, or injury (31-33). TNF and IL-1 $\beta$ activate endothelial cells, attracting polymorphonuclear cells and monocytes to the site of inflammation and enhancing their movement through the blood. IL-8 is a chemokine, acting as a monocyte chemoattractant, and it is later responsible for IL-10 synthesis $(33,34)$. Antigen-presenting cells secrete IL-1 $\beta$, which promotes $T$ cell activation. When activated, Th1-related cells secrete IFN- $\gamma$ that activates macrophages to secrete more IL-12. In our study, iPPVO treatment resulted in a prompt stimulus on these proinflammatory cytokines during the early response.

Increased expression of Th1-related cytokine mRNA (IL-12 and IFN- $\gamma$ ) was detected from 24 to $96 \mathrm{hpi}$, with 
mRNA peaks at $24 \mathrm{hpi}(\mathrm{IFN}-\gamma)$ and $48 \mathrm{hpi}$ (IL-12). With the use of ELISA, a similar profile was observed, with IL12 peaking earlier $(24 \mathrm{~h})$ and IFN- $\gamma$ at $48 \mathrm{hpi}$. These data are consistent with previous studies showing that antiviral activity of iPPVO against genital herpes in guinea pigs and murine hepatitis virus in a mouse model was strongly associated with the Th1-related immune response, especially IL-2, IL-8, and IFN- $\gamma$ (18). In this model, IFN$\gamma$ was defined as the key mediator of antiviral activity. The induction of a Th1-type immune response by iPPVO has been detected in different species, and it has been suggested that this response is elicited by the viral particles themselves $(11,15,30)$. These effects have also been demonstrated in vivo, because young horses treated with iPPVO intramuscularly or intradermally showed a transient increase in IFN- $\gamma$ gene expression in blood cells or locally, respectively, at 24-48 hpi (19). Taken together, these results suggest that IFN- $\gamma$ synthesis by $\mathrm{T}$ lymphocytes and/or NK cells, thus directing a Th1-type response, plays a pivotal role in iPPVO-immunostimulatory activity (32).

The inflammatory and Th1 response observed at early times after iPPVO stimulation are usually limited by

\section{References}

1. Haig DM. Orf virus infection and host immunity. Curr Opin Infect Dis 2006; 19: 127-131, doi: 10.1097/01.qco.0000216622. 75326.ef.

2. Buttner M, Rziha HJ. Parapoxviruses: from the lesion to the viral genome. J Vet Med B Infect Dis Vet Public Health 2002; 49: 7-16, doi: 10.1046/j.1439-0450.2002.00539.x.

3. Nougairede A, Fossati C, Salez N, Cohen-Bacrie S, Ninove $\mathrm{L}$, Michel $\mathrm{F}$, et al. Sheep-to-human transmission of Orf virus during Eid al-Adha religious practices, France. Emerg Infect Dis 2013; 19: 102-105, doi: 10.3201/eid1901.120421.

4. Haig DM, Mercer AA. Ovine diseases. Orf. Vet Res 1998; 29: 311-326.

5. Haig DM, Mclnnes C, Deane D, Reid H, Mercer A. The immune and inflammatory response to orf virus. Comp Immunol Microbiol Infect Dis 1997; 20: 197-204, doi: 10.1016/S0147-9571(96)00045-8.

6. Haig DM, Mclnnes CJ. Immunity and counter-immunity during infection with the Parapoxvirus orf virus. Virus Res 2002; 88: 3-16, doi: 10.1016/S0168-1702(02)00117-X.

7. Deane D, Ueda N, Wise LM, Wood AR, Percival A, Jepson $\mathrm{C}$, et al. Conservation and variation of the parapoxvirus GMCSF-inhibitory factor (GIF) proteins. J Gen Virol 2009; 90: 970-977, doi: 10.1099/vir.0.006692-0.

8. Diel DG, Delhon G, Luo S, Flores EF, Rock DL. A novel inhibitor of the NF-\{kappa\}B signaling pathway encoded by the Parapoxvirus orf virus. J Virol 2010; 84: 3962-3973, doi: 10.1128/JVI.02291-09.

9. Diel DG, Luo S, Delhon G, Peng Y, Flores EF, Rock DL. A nuclear inhibitor of NF-kappaB encoded by a poxvirus. J Virol 2011; 85: 264-275, doi: 10.1128/JVI.01149-10.

10. Diel DG, Luo S, Delhon G, Peng Y, Flores EF, Rock DL. Orf virus ORFV121 encodes a novel inhibitor of NF-kappaB that subsequent upregulation of regulatory and Th2 cytokines, namely IL-1RA and IL-10, followed by IL-4 $(18,29)$. The late upregulation of IL-1R (a natural antagonist of IL-1 $\beta$ ), IL-10 (a regulatory cytokine), and IL-4 (a Th2 cytokine and Th1 cytokine antagonist) in PBMCs could explain the absence of notable side effects or tissue damage after iPPVO administration $(15,18)$. Consistent with these findings, in the present study, induction of Th2-regulatory cytokines (IL-10, IL-4) was detected at later times, noticeably at 48-72 hpi (IL-10) and 72-96 hpi (IL-4) (Figure 3).

In summary, our results confirm and extend the previous findings that iPPVO exerts a strong effect on cytokine expression by immune cells, leading to an initial induction of proinflammatory and Th1-related cytokines followed by a Th2 regulatory-cytokine response. An understanding of the regulatory mechanisms and effects is key to be able to manipulate the immune response and use iPPVO effectively as an immunostimulant or therapeutic aid in human and animal infectious diseases that are difficult to treat. In addition, the present study illustrates the usefulness of having a combination of molecular mechanisms, immunoassays, and biological assays to measure cytokine response. contributes to virus virulence. J Virol 2011; 85: 2037-2049, doi: 10.1128/JVI.02236-10.

11. Weber $O$, Mercer AA, Friebe A, Knolle $P$, Volk HD. Therapeutic immunomodulation using a virus - the potential of inactivated orf virus. Eur J Clin Microbiol Infect Dis 2013; 32: 451-460, doi: 10.1007/s10096-012-1780-x.

12. Forster R, Wolf G, Mayr A. Highly attenuated poxviruses induce functional priming of neutrophils in vitro. Arch Virol 1994; 136: 219-226, doi: 10.1007/BF01538831.

13. Fachinger V, Schlapp T, Strube W, Schmeer N, Saalmuller A. Poxvirus-induced immunostimulating effects on porcine leukocytes. J Virol 2000; 74: 7943-7951, doi: 10.1128/ JVI.74.17.7943-7951.2000.

14. Winnicka A, Klucinski W, Kawiak J, Hoser G, Sikora J. Effect of Baypamun on blood leucocytes in normal and dexamethasone treated goats. J Vet Med A Physiol Pathol Clin Med 2000; 47: 385-394, doi: 10.1046/j.1439-0442.2000.00298.x.

15. Friebe $A$, Siegling A, Friederichs S, Volk HD, Weber $O$. Immunomodulatory effects of inactivated Parapoxvirus ovis (ORF virus) on human peripheral immune cells: induction of cytokine secretion in monocytes and Th1-like cells. J Virol 2004; 78: 9400-9411, doi: 10.1128/JVI.78.17.9400-9411.2004.

16. Schutze N, Raue R, Buttner M, Alber G. Inactivated Parapoxvirus ovis activates canine blood phagocytes and T lymphocytes. Vet Microbiol 2009; 137: 260-267, doi: 10.1016/j.vetmic.2009.01.035.

17. Siegemund $S$, Hartl A, von Buttlar H, Dautel F, Raue R, Freudenberg MA, et al. Conventional bone marrow-derived dendritic cells contribute to Toll-like receptor-independent production of alpha/beta interferon in response to inactivated Parapoxvirus ovis. J Virol 2009; 83: 9411-9422, doi: 10.1128/JVI.02362-08. 
18. Weber O, Siegling A, Friebe A, Limmer A, Schlapp T, Knolle $\mathrm{P}$, et al. Inactivated Parapoxvirus ovis (Orf virus) has antiviral activity against hepatitis $B$ virus and herpes simplex virus. J Gen Virol 2003; 84: 1843-1852, doi: 10.1099/vir.0.19138-0.

19. Horohov DW, Breathnach CC, Sturgill TL, Rashid C, Stiltner $\mathrm{JL}$, Strong D, et al. In vitro and in vivo modulation of the equine immune response by Parapoxvirus ovis. Equine Vet J 2008; 40: 468-472, doi: 10.2746/042516408X322111.

20. Ryan C, Giguere S, Fultz L, Long MT, Crawford PC. Effects of two commercially available immunostimulants on leukocyte function of foals following ex vivo exposure to Rhodococcus equi. Vet Immunol Immunopathol 2010; 138: 198-205, doi: 10.1016/j.vetimm.2010.07.027.

21. Sturgill TL, Giguere S, Franklin RP, Cohen ND, Hagen J, Kalyuzhny AE. Effects of inactivated Parapoxvirus ovis on the cumulative incidence of pneumonia and cytokine secretion in foals on a farm with endemic infections caused by Rhodococcus equi. Vet Immunol Immunopathol 2011; 140: 237-243, doi: 10.1016/j.vetimm.2010.12.012.

22. Brum MC, Anjos BL, Nogueira CE, Amaral LA, Weiblen R, Flores EF. An outbreak of orthopoxvirus-associated disease in horses in southern Brazil. J Vet Diagn Invest 2010; 22 : 143-147, doi: 10.1177/104063871002200132.

23. Reed L, Muench HA. Simple method of estimating fifty percent endpoints. Am J Hyg 1938; 27: 493-497.

24. Bustin SA, Benes V, Garson JA, Hellemans J, Huggett J, Kubista $M$, et al. The MIQE guidelines: minimum information for publication of quantitative real-time PCR experiments. Clin Chem 2009; 55: 611-622, doi: 10.1373/clinchem.2008.112797.

25. Altschul SF, Madden TL, Schaffer AA, Zhang J, Zhang Z, Miller W, et al. Gapped BLAST and PSI-BLAST: a new generation of protein database search programs. Nucleic Acids Res 1997; 25: 3389-3402, doi: 10.1093/nar/25.17.3389.

26. Livak KJ, Schmittgen TD. Analysis of relative gene expression data using real-time quantitative PCR and the 2(-Delta Delta C(T)) Method. Methods 2001; 25: 402-408, doi: 10.1006/meth.2001.1262.

27. Vogel SN, Friedman RM, Hogan MM. Measurement of antiviral activity induced by interferons alpha, beta, and gamma. Curr Protoc Immunol 2001; 6: 6-9.

28. Green JA, Yeh TJ, Overall JC Jr. Rapid, quantitative, semiautomated assay for virus-induced and immune human interferons. J Clin Microbiol 1980; 12: 433-438.

29. Paillot R. A systematic review of the immune-modulators Parapoxvirus ovis and Propionibacterium acnes for the prevention of respiratory disease and other infections in the horse. Vet Immunol Immunopathol 2013; 153: 1-9, doi: 10.1016/j.vetimm.2013.01.010

30. Friebe A, Friederichs S, Scholz K, Janssen U, Scholz C, Schlapp T, et al. Characterization of immunostimulatory components of orf virus (Parapoxvirus ovis). J Gen Virol 2011; 92: 1571-1584, doi: 10.1099/vir.0.028894-0.

31. Schutze N, Raue R, Buttner M, Kohler G, McInnes CJ, Alber G. Specific antibodies induced by inactivated Parapoxvirus ovis potently enhance oxidative burst in canine blood polymorphonuclear leukocytes and monocytes. Vet Microbiol 2010; 140: 81-91, doi: 10.1016/j.vetmic.2009.07.027.

32. Ahne W, Mayr A. Poxvirus preparation CONPIND initiates production of the major inflammatory mediators IL-1 alpha and TNF-alpha in human whole blood and in blood mononuclear cell cultures. Comp Immunol Microbiol Infect Dis 1997; 20: 139-145, doi: 10.1016/S0147-9571(96)00040-9.

33. Arai KI, Lee F, Miyajima A, Miyatake S, Arai N, Yokota T. Cytokines: coordinators of immune and inflammatory responses. Annu Rev Biochem 1990; 59: 783-836, doi: 10. 1146/annurev.bi.59.070190.004031.

34. Dinarello CA. Proinflammatory cytokines. Chest 2000; 118 : 503-508, doi: 10.1378/chest.118.2.503. 